\title{
A qualitative evaluation of a new community living model: medical foster home placement
}

\author{
Cari R. Levy ${ }^{1}$, J acqueline J ones ${ }^{2}$, Leah M. Haverhals ${ }^{3}$, Carolyn T. Nowels ${ }^{1}$ \\ 1. Denver Veterans Affairs Medical Center and the University of Colorado Denver, Denver, the United States. 2. College of \\ Nursing, University of Colorado Denver, Denver, the United States. 3. Denver Veterans Affairs Medical Center, Denver, the \\ United States.
}

Correspondence: Cari R. Levy. Address: Denver Veterans Affairs Medical Center and the University of Colorado Denver, 1055 Clermont St (151), Denver, the United States. Email: cari.levy@va.gov

Received: March 6, 2013

DOI : $10.5430 /$ jnep.v4n1p162
Accepted: May 23, 2013

URL: http://dx.doi.org/10.5430/jnep.v4n1p162

\section{Abstract}

Background: The Department of Veterans Affairs (VA) Medical Foster Home (MFH) program is an alternative to nursing home $(\mathrm{NH})$ placement for veterans who are NH-eligible but prefer to receive care in private homes. Program expansion is ongoing; however, inefficiencies exist in targeting Veterans for enrollment.

Methods: Semi-structured interviews were conducted with 35 individuals, 9 national MFH coordinators, 14 Primary Care Team Members, 2 veterans living in MFHs, 4 of their family members, 3 caregivers, and 3 family members of veterans who declined to participate in the program. Transcripts were analyzed using a general inductive approach supported by Archive for Technology, Lifeworld and Everyday language, text interpretation (ATLAS ti) V6.2.

Results: Three themes were identified as key facilitators of successful MFH placement: 1) The Environment - veterans needed to have appropriate and comfortable physical space that ensured safety and was in a desirable geographic location; 2) The Match - a collaborative relationship between veterans, care providers, and the medical team providing care within the home was essential; and 3) Perceptions and Expectations about the ability for needs to be met in MFHs and challenges related to health concerns, relocation, and costs. These themes, when integrated into the Social Ecological Model, provide a theoretical framework from which to guide future research and understand policy implications.

Conclusions: MFHs represent a novel alternative to $\mathrm{NH}$ placement. This evaluation provides an understanding of factors that lead to successful MFH placement and integrates these themes into a theoretical framework designed to assist both VA policymakers interested in expanding the program and those within the civilian community seeking to study alternatives to traditional $\mathrm{NH}$ care.

\section{Key words}

Veteran, Nursing home, Medical foster home, Residential care, Qualitative methods

\section{I ntroduction}

The United States Department of Veterans Affairs (VA) Medical Foster Home (MFH) program was created as a VA alternative to nursing home $(\mathrm{NH})$ accommodation for NH-eligible Veterans who prefer to live within the community and receive care in private homes with qualified, 24/7 caregivers ${ }^{[1]}$. The MFH program was piloted first in 2000, officially 
beginning with three sites in 2008. Currently, 67 sites are in some phase of initiating this innovative care delivery model. Nationwide a total of 1,911 Veterans have participated since the MFH program's inception ${ }^{[1]}$.

The MFH program focuses on the following goals: 1) optimizing Veterans' quality of life, 2) providing a safe alternative to institutional care, 3) integrating care of Veterans into the community and 4) assuring patient and caregiver safety. The MFH program uses a home-based primary care (HBPC) model for medical care using an interprofessional team (advance practice nurses, social workers, physical and occupational therapists, nutritionists, pharmacists etc.) to provide in-home care to homebound Veterans who have great difficulty attending clinic visits due to advanced, chronic, complex, comorbid diseases. The HBPC team seeks to provide all care in the home with a goal of maintaining function, minimizing institutionalization, and maintaining quality of life.

A Veteran can choose to enroll in the MFH program, often supported by their family due to cognitive challenges, and once placed in a home can also reassess the "fit" and be placed elsewhere. The MFH caregiver is contracted to the Veteran independent of the VA and the Veteran assumes accommodation charges, averaging $\$ 1500-\$ 3000 /$ month $^{[1]}$. The VA supplies the HBPC team as well as oversight by a MFH program coordinator. Operational costs to the VA are approximately \$1,500 per month per Veteran enrolled in MFH, which is less than half the cost of traditional NH care ${ }^{[2]}$. To date, the majority of Veterans who enroll in a MFH program remain in the MFH until death or transition to a less restrictive care facility (assisted living or home with family) ${ }^{[3]}$. Of the Veterans in the MFH program (all of whom are, by definition, $\mathrm{NH}$ eligible), less than $15 \%$ require $\mathrm{NH}$ placement ${ }^{[3]}$. These statistics are compelling because the VA currently pays for $\mathrm{NH}$ care to over 17,000 Veterans daily at a projected annual cost of $\$ 4.9$ billion in Fiscal Year $12^{[4,5]}$. The MFH program represents an alternative to institutional care for Veterans with substantial cost savings for the VA. MFH also has the potential to inform Medicare's Independence at Home Initiative, a demonstration designed to evaluate alternatives to institutional care for NH-eligible beneficiaries ${ }^{[6]}$. Since the MFH program expanded, two barriers to enrollment have been identified. First, MFH coordinators estimate that only 1 of 10 Veterans referred to the program actually chose to enroll in it. Second, while the program has steadily increased enrollment, this increase has not been observed across all sites; at least half enroll fewer than 10 Veterans in their first year. The purpose of this qualitative evaluation is to identify key ingredients of successful MFH placement as an initial step to understanding how to refine recruitment strategies. Placement is defined as the enrollment of a Veteran to a MFH program in the context of decision support by "family" and eligibility as determined by the program providers. We aimed to define why Veterans and their family chose MFH and to identify factors that influenced those decisions.

Questions guiding the inquiry included:

1) What does a successful MFH placement look like and what are its key features in terms of structure, process, and perceived outcomes?

2) Who are the key stakeholders involved in MFH success?

3) How does the MFH program facilitate Veteran engagement with the program?

Using a local level snapshot of a small MFH program in one large western state (Colorado), we used individual and group interviews to generate data about the context of MFH placement and what makes the MFH a success from the perspective of those involved.

This evaluation was approved by the Colorado Multiple Institutional Review Board and the Denver VA Research and Development Committee and formed the foundation for a national study (VA HSR\&D CRE-12-029).

\section{Methods}

This evaluation adopts participant views as situated knowledge to develop patterns of meanings not predetermined by an existing theory ${ }^{[7]}$. A qualitative descriptive design was used to explore what makes a MFH program placement success- 
ful ${ }^{[8]}$. It provides access to participant perceptions of a situation and allows for an "on the ground" examination of success factors and contextual challenges related to MFH placement using participant language and meaning ${ }^{[7]}$.

Information rich individuals were sought who could share experiences about 1) The process involved in referring to a MFH program (predisposing characteristics); 2) The decision to be placed in a MFH or not (enabling factors); 3) Provision of care to Veterans within a MFH program (health care needs and quality of care); and 4) Facilitators and barriers related to maintaining a MFH program (safety and cost). Interview guides (see Figure 1A-1F) were developed around these key areas based on the literature, clinical experiences, and iteratively refined by new participant descriptions throughout the process. Given the need to explore the context of MFH success, a convenience sample ${ }^{[7]}$ of key MFH program stakeholders at the individual, organizational, and national level were identified. All participation was voluntary and uncompensated.

Figure 1A. Sample Interview Questions: Medical Foster Home Family Member

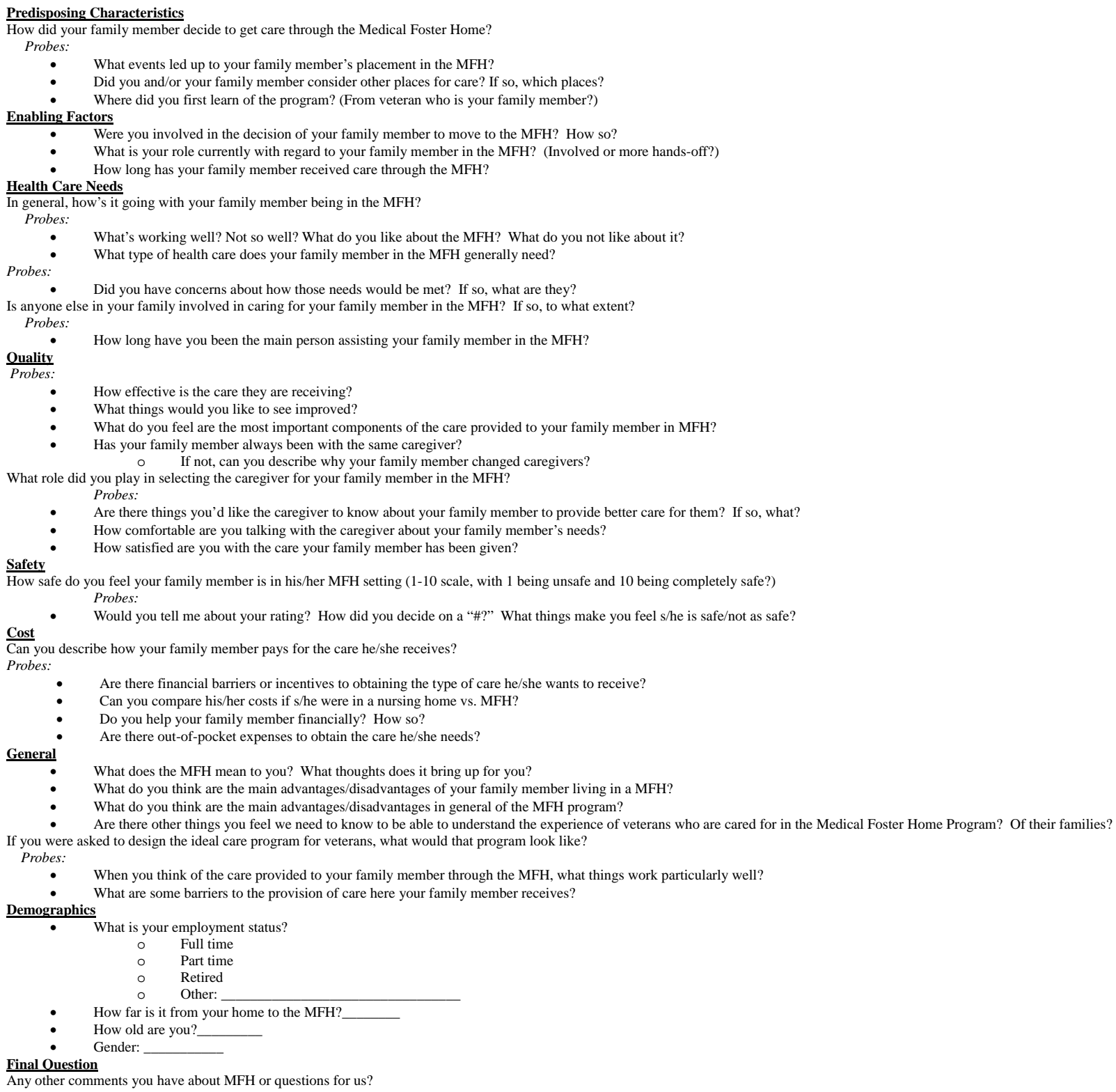


Figure 1B. Sample Interview Questions: Medical Foster Home Decliners Family Member

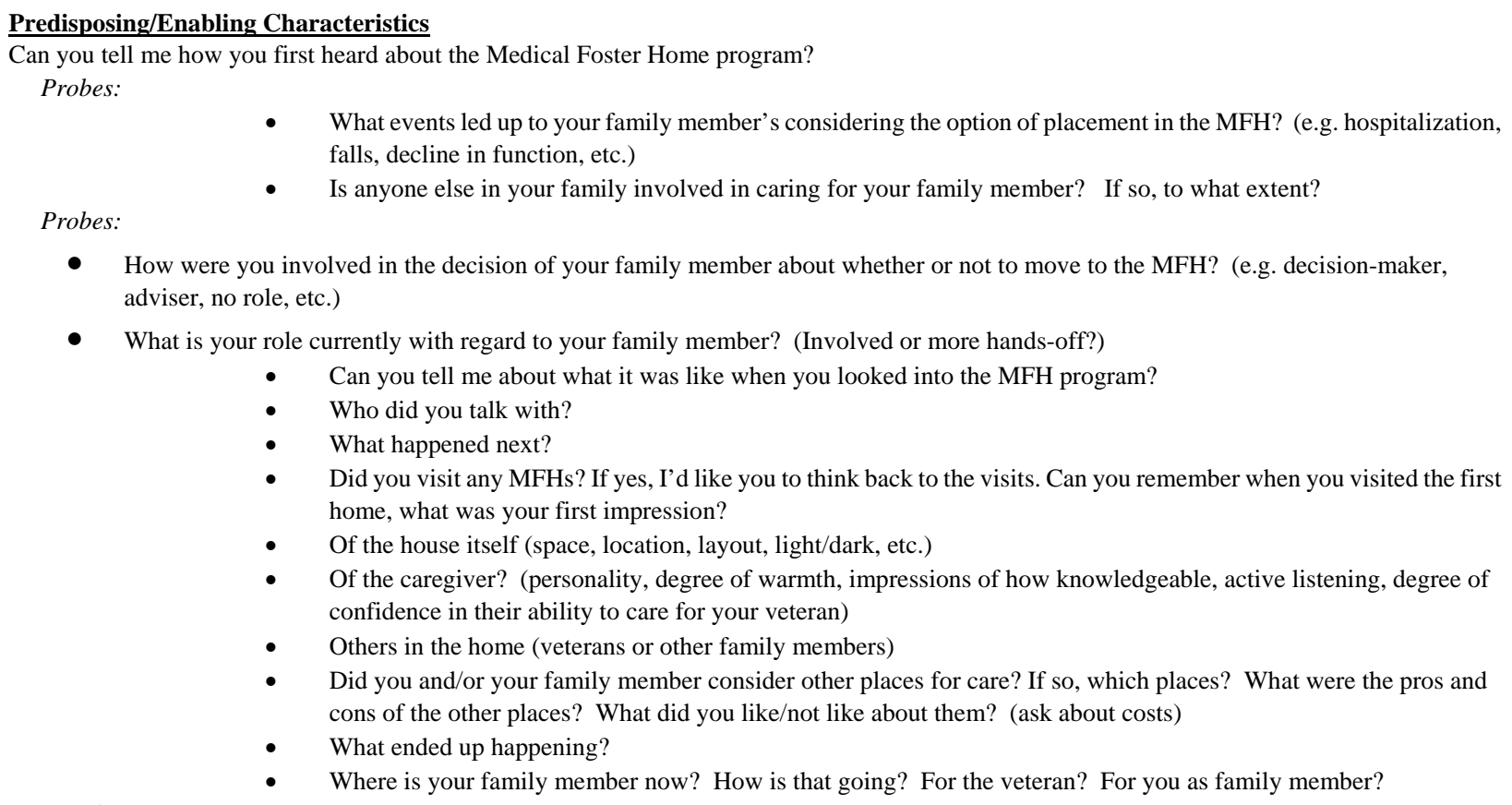

- What events led up to your family member's considering the option of placement in the MFH? (e.g. hospitalization, falls, decline in function, etc.)

Probes:

- $\quad$ Is anyone else in your family involved in caring for your family member? If so, to what extent?

- How were you involved in the decision of your family member about whether or not to move to the MFH? (e.g. decision-maker, adviser, no role, etc.)

- What is your role currently with regard to your family member? (Involved or more hands-off?)

- $\quad$ Can you tell me about what it was like when you looked into the MFH program?

- Who did you talk with?

- What happened next?

- $\quad$ Did you visit any MFHs? If yes, I'd like you to think back to the visits. Can you remember when you visited the first home, what was your first impression?

- $\quad$ Of the house itself (space, location, layout, light/dark, etc.)

- Of the caregiver? (personality, degree of warmth, impressions of how knowledgeable, active listening, degree of confidence in their ability to care for your veteran)

- $\quad$ Others in the home (veterans or other family members)

- $\quad$ Did you and/or your family member consider other places for care? If so, which places? What were the pros and cons of the other places? What did you like/not like about them? (ask about costs)

- What ended up happening?

- Where is your family member now? How is that going? For the veteran? For you as family member?

Health Care Needs

What type of health care does your family member generally need?

Probes:

Quality

- Did you have concerns about how those needs would be met in the MFH? If so, what are they?

Probes:

One of the most important things to family member is the quality of care provided to their veteran. Can you tell me what you thought about the QOC in the MFH's you visited? Was there anything you were concerned about with regard to the care that would be provided?

Safety

How safe did you feel your family member would be in his/her MFH setting (1-10 scale, with 1 being unsafe and 10 being completely safe?) Probes:

- Would you tell me about your rating? How did you decide on a “\#?” What things made you feel s/he is safe/not as safe?

$\underline{\text { Cost }}$

- Understandably families are concerned about the cost of different types of care for their veteran. How did the cost figure into your decision about MFH vs. other placements? Can you compare his/her costs if s/he were in a nursing home vs. MFH?

General

- When you first heard the term "MFH” what thoughts did it bring up for you?

- What do you think would be the main disadvantages of your family member living in a MFH? What about advantages?

- Some people have said that it would be hard to know what it would actually be like to live at the MFH. One of the ideas that has come up is "try before you buy" where the veteran can choose to spend an overnight at the MFH to see what it's like to be there for 24 hours. As a family member, what do you think of this idea?

- $\quad$ If you were asked to design the ideal care program for veterans, what would that program look like?

Demographics

- What is your employment status?
o Full time
o Part time
o Retired
o Other:

- How far is was it from your home to the MFH(s) you visited?

- How old are you?

- Gender:

Final Question

- $\quad$ Any other comments you have about MFH or questions for us? 
Figure 1C. Sample Interview Questions: Medical Foster Home Caregiver

\section{Predisposing Characteristics}

Can you describe the events that led you to become a caregiver in the VA MFH program?

Probes:

- How did you learn of the program?

- What type of work history do you have related to care giving?

- How long have you served as a caregiver with the MFH?

\section{Enabling Factors}

- Who was involved in the decision as to which veteran you would provide care for?

- How long did the process take to be matched with a veteran?

- $\quad$ To what extent is the family involved with the veteran(s) you care for?

- Have you cared for a veteran through MFH before? If so, when?

\section{Background}

Can you tell us about your job responsibilities in your role as Denver MFH Caregiver?

\section{Health Care Needs}

What type of health care do the veterans you care for through the MFH generally need?

Probes:

- Did/do you have concerns about how those needs would be met? If so, what are they?

- Has it been challenging providing for the veteran's health care needs?

- If so, how so?

\section{Quality}

What do you see as most important to the veterans in the MFH?

Probes:

- What do you feel are the most important components of the care provided to veterans in MFH?

Can you describe the communication process between yourself and:

- the veteran

- the family

- $\quad$ Other health care providers/MFH coordinator in order to provide adequate care for the veteran?

Safety

How safe do you think the veteran you care for feels here? (1-10, with 10 being safest)

Probes:

- $\quad$ Can you tell me about your rating?

- If not, what makes them feel unsafe?

- If so, why do you think they feel safe here?

$\underline{\text { Cost }}$

How do you and family members of the veteran work out paying for other needs of the veteran?

- Is the veteran you care for limited in any way by financial constraints?

- How satisfied are you with the compensation you receive?

\section{General}

- What do you think are the main advantages/disadvantages of serving as a caregiver with the MFH program?

- What do you think are the main advantages/disadvantages are in general of the MFH program?

- $\quad$ Any challenges with being a caregiver?

- $\quad$ Any rewards with being a caregiver?

- $\quad$ Are there other things you feel are important in understanding the experience of veterans who are cared for in the Medical Foster Home Program?

If you were asked to design the ideal care program for veterans, what would that program look like?

Probes:

- When you think of the care provided here, what things work particularly well?

- What are some barriers to the provision of care here?

Anything else you'd like to add? 
Figure 1D. Sample Interview Questions: Veteran

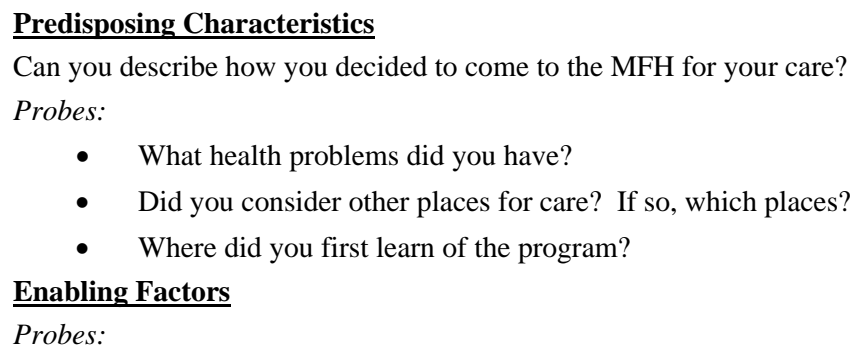

- $\quad$ Looking ahead, how long do you plan to stay here?

- Who has been involved in your care since you first came to the MFH?

- Who else (if anyone) helped you decide to get care through a MFH?

- When you were thinking of moving here, what were your concerns?

- How long have you received care here?
a. Where were you living before? What happened?

- We're interested in hearing people's opinions on the name 'Medical Foster Home' — what did you think when you first heard it?

\section{Health Care Needs}

What type of health care do you need?

Probes:

- How do you feel your health care needs are being met here?

- $\quad$ Did you have concerns about how those needs would be met? If so, what were they?

\section{Quality}

What do you feel is the most important part of the care you are receiving right now?

Probes:

- How would you rate the care you're receiving here? (1-10, with 10 being terrible, 10 outstanding)

- Can you tell me about your rating?

- What things would you like to see improved?

How knowledgeable is your caregiver about the care they are providing to you?

Probes:

- What do they need to be more knowledgeable about?

- $\quad$ Are there things you'd like your care provider to know more about? If so, what?

\section{Safety}

How safe do you feel here? (1-10, with 10 being safest)

Probes:

- $\quad$ Can you tell me about your rating?

- What makes you feel unsafe?

- What makes you feel safe?

Cost

How do you pay for your care?

Probes:

- Is your life here limited in any way financially?

- Do you have to spend extra money out-of-pocket to obtain the care/things you need?

\section{General}

- What do you think are the main advantages/disadvantages of living in a MFH?

- What do you think are the main advantages/disadvantages of the MFH program?

- When you think of the care provided here, what things work particularly well?

- What are some things you would improve?

- Are there other things you feel we need to know to be able to understand your experience in the Medical Foster Home Program?

- If you were asked to design the ideal care program for veterans like yourself, what would that program look like? Anything else you would like to add? 


\section{Figure 1E. HBPC Team Focus Group Question Guide}

Intro: Explore Vision/Values related to HBPC: How put values into action. How values guide day-to-day role. How see skills as HBPC providers of MFH care-is it different than non-MFH residents?

1. Predisposing Characteristics

- Can you tell us how you are involved in the referral and/or selection process of veterans to be placed in MFHs? Can you describe the role you play between the caregivers and veterans and Judy, the MFH coordinator?

- What veteran characteristics do you see as most important in selection of who might be most appropriate for Medical Foster Home placement?

- What do you see as the "key ingredients" for a good "match" or "fit" between a veteran and a caregiver?

- Probes:

- How do veterans generally learn of the program?

- Have you seen any trends of certain types of veterans who choose MFH? If so, what?

- What about family characteristics of the veterans placed in MFH? Are there some characteristics that make for a better MFH "match" or "fit?"

- Can you tell us how you're involved in the referral and/or selection process of caregivers for the MFH program? What factors do you see as most important in selection of the Medical Foster Home caregivers?

Probes:

- What words would you use to describe the ideal caregiver?

- How would you describe placements that did not work out because of caregiver issues?

- What's different between the ideal and less-than-ideal caregivers?

2. Enabling Factors

Are you able to describe the events that have led veterans under your care to seek care via the MFH?

Probes:

- Who was involved in the decision of the veterans in MFHs to move there?

- Were families involved with MFH veterans' decisions or were they generally on their own? How did that work?

- We've heard some families are a "tough sell." What does that mean to you? Can you describe how that plays out in the MFH program in Denver?

- One thing that has helped with referrals

If you had to choose one thing that you think would help with veteran referrals, what would you choose?

- $\quad$ One thing that has helped with participation

If you had to choose one thing that you think would help most with veterans deciding to participate in MFH program, what would you choose?

- One thing that has helped with families placing their veteran

What about one thing that helped families agreeing to place their veteran in a MFH?

3. Barriers to recruitment/retention of veterans \& recruitment of caregivers

Can you tell me what things you see getting in the way of recruiting veterans for MFHs? Probes

- $\quad$ Lack of marketing reaching the desired population?

- $\quad$ Lack of "buy-in" (from whom?)

- Misperceptions about what MFH is/does?

- Other?

- What things do you think get in the way of recruiting high-quality caregivers for MFHs?

4. Health Care Needs

What type of health care do the veterans in MFH's generally need? Is their care different from other HBPC patients? Can you describe?

Probes

- $\quad$ Type of needs: equipment, dealing with CG rather than family members?

- $\quad$ Needs change over time? Is so, how?

- Has your relationship with the MFH vet(s) changed over time? If so, in what way? In terms of mood and satisfaction of the vets, what's your sense of how the placements are working? What kinds of things do vets bring up with you? (Example: some vets may mention issues in the MFH, e.g. they cannot listen to their radio during the daytime b/c a family member works nights and needs to sleep during the day. Or perhaps they don't get along with another vet in the home.)

5. Quality

What do you feel are the most important components of the care provided to veterans in MFH?

Probes:

- What do you think the veterans see as most important part of their care in the MFH? How do you know?

6. $\quad$ Safety

How safe do you feel the veterans are in the MFH setting? How safe do you think they feel?

Probes:

- What do you think makes them feel safe/unsafe? Can you give me examples?

7. Key Ingredients

Overall: what would you say are the key ingredients to create a highly successful MFH program?

- If you were asked to design the ideal care program for veterans, what would that program look like?

Probes:

- When you think of the care provided, what things work particularly well?

- What are some barriers to the provision of care here?

8. Anything else?

Are there other things you feel are important in understanding the experience of veterans who are cared for in the Medical Foster Home Program?

What advice would you give to someone who is starting up a MFH program in a new location?

9. $\quad$ Ask permission to re-contact if we have further questions.

10. THANK YOU-include words of appreciation from Research Team 
Figure 1F. MFH Coordinator and Program Assistant Focus Group Question Guide

Intro: Explore Vision/values related to MFH: How put values into action. How values guide day-to-day role

1. Predisposing Characteristics

Are there veteran characteristics that seem important in selection of the Medical Foster Home for care?

Probes:

- How do veterans generally learn of the program?

- Have you seen any trends of certain types of people who choose MFH? If so, what?

2. Enabling Factors

Can you describe the events that lead veterans to seek care via the MFH?

Probes:

- Who is usually involved in the decision of the veterans in MFHs to move there?

- $\quad$ Are families generally involved with MFH veterans' decisions or are they generally on their own? How does that work? We've heard some families are a "tough sell." What does that mean to you? Can you describe how that plays out in your program?

- If you had to choose one thing that you think has helped most with veteran referrals, what would you choose?

- If you had to choose one thing that you think has helped most with veterans deciding to participate in MFH program, what would you choose?

- $\quad$ One thing that has helped with families placing their veteran

- What about one thing that helped most with families agreeing to place their veteran in a MFH?

3. Barriers to recruitment/retention of veterans

Can you tell me about things that get in the way of recruiting veterans for your MFHs?

Probes:

- $\quad$ Lack of marketing reaching the desired population?

- $\quad$ Lack of "buy-in” (from whom?)

- Misperceptions about what MFH is/does?

- Other?

4. Health Care Needs

What type of health care do the veterans in MFH's generally need?

Probes:

- $\quad$ Can you describe the role you play between the caregivers and veterans?

- Do health care needs generally change over time?

- What happens if needs of the veteran change over time?

5. Recruitment of caregivers

Can you tell me what strategies you use for recruiting caregivers? What works well/not so well?

Probes:

- $\quad$ Are there particular characteristics of CGs that seem to predict more successful placement?

- Are there particular characteristics of CGs that, on the other hand, seem to predict less successful placement?

6. Quality

What do you feel are the most important components of the care provided to veterans in MFH?

Probes:

- What do you see as most important to the veterans in the MFH? How do you know?

7. Safety

How safe do you feel the veterans are in the MFH setting? How safe do you think they feel?

Probes:

- What do you think makes them feel safe/unsafe? Can you give me examples?

8. Cost

Can you describe how the veterans in your program pay for the care they receive?

Probes:

- $\quad$ Are there financial barriers to obtaining the type of care they want to receive?

- What is the process of payment? How does that work? Do you help with that?

9. Key Ingredients

Overall: what would you say are the key ingredients for the success of your program?

- If you were asked to design the ideal care program for veterans, what would that program look like?

Probes:

- When you think of the care provided at your site, what things work particularly well?

- What are some barriers to the provision of care here?

10. Anything else?

Are there other things you feel are important in understanding the experience of veterans who are cared for in the Medical Foster Home Program? What advice would you give to someone who is starting up a MFH program in a new location?

11. Ask permission to re-contact if we have further questions. Also ask if they would be willing to send us any materials related to their program (e.g. literature, pamphlets, marketing materials, staff guides, etc.).

12. THANK YOU-include words of appreciation from Research Team 


\subsection{Data collection}

Semi-structured interviews at the level of the individual Veteran, caregiver, and family member allow for exploration of specific experiences where MFH participants or those who declined MFH placement could describe their decisions ${ }^{[9]}$. Focus groups provide insight into the "natural" group understandings of the MFH program, what works, system level challenges, and how national policy influences day to day functioning from their perspective. Interaction between group members is actively encouraged to refine and contextualize group knowledge ${ }^{[9]}$. Both individual and group interviews were conducted in parallel, digitally recorded, transcribed for analysis, and reviewed for accuracy. During all phases of data collection and analysis our interprofessional qualitative team reviewed protocols, interview guides, and interim findings. We used semi-structured guides, initially framed around topics relevant to the MFH program and iteratively developed regarding language or topics shared by participants ${ }^{[7]}$.

\subsection{Qualitative analysis}

Data included field notes and interview and focus group transcriptions. Within a General Inductive Approach (GIA) to evaluation ${ }^{[10]}$, an inductive and deductive, systematic, team based ${ }^{[7]}$ toolkit was used for data reduction, analysis, and data display supported by Atlas Ti v6.2 software ${ }^{[10,11]}$. GIA includes the following 6 steps: 1 ) interview guide provides predetermined deductive codes; 2) new inductive codes emerge from participants' own words, and their context. Together these codes are considered for similarities and differences. Discrepancies are revised based on consensus and 3) synthesized into a core set of codes; 4) Codes are organized into a network diagram representing the breadth of the overall "landscape", a process model of VA MFHs placement, key concepts, themes, and relationships; 5) Themes are then collapsed and synthesized into between 3 to 8 major components as related to the evaluation aims; 6) The final stage of the GIA involves interpretation of findings using existing theory ${ }^{[10]}$.

\section{Results}

Over a 3 month period (July-September 2011) a snowball sampling approach ${ }^{[7]}$ was used to recruit key stakeholders for two interprofessional focus groups (FGs) of 90 minute duration. The first FG was composed of MFH Coordinators/ Program Assistants ( $n=9)$ from across the US. The second FG included members of the HBPC team $(n=14)$ at Eastern Colorado Health Care System (ECHCS). Discussion emphasized the process of placing Veterans in the MFH, associated barriers and facilitators, and characteristics of a "good match" between Veteran and caregiver; these varied by discipline and position, views, and perspectives ${ }^{[9]}$. The ECHCS MFH Coordinator facilitated recruitment of a small purposive sample of MFH consumers ( $(n=13)$ including Veterans $(n=2)$, caregivers $(n=3)$, and family members of Veterans who either accepted or declined MFH placement $(n=7)$. The sample pool of eligible Veterans was 10, of those 9 were cognitively able to participate. Individual interviews lasting 30-60 minutes were conducted in person or by phone depending on participant preference ${ }^{[7]}$. We then compared the in-depth experiences of the total 35 participants with organizational agendas of the VA and national priorities. Evolving analysis was checked for authenticity through local and national presentations with stakeholders who provide or influence Veteran care, member checking was conducted by iterative analysis across participant interviews/focus groups, and interprofessional team perspectives enhanced credibility and trustworthiness of final analysis.

A network diagram illustrating preliminary MFH placement process codes [n $=27$ ], concepts, and relationships was developed (see Figure 2). Themes describing “a successful MFH placement” clustered around the concept of balance between facilitating factors and barriers to MFH placement that determined the degree of "fit" of the MFH and Veteran. Three major components were then identified within which vital factors to success were grouped: 1) Environment; 2) The match: respect and relationships; and 3) Perceptions and expectations about Veterans' needs and MFHs (see Table 1).

Table 1. Participants: Medical Foster Home Interviews and Focus Groups

\begin{tabular}{llllll}
\hline Focus Groups (2) & Veterans & Family Members & Caregivers & Family Members of Decliners & Total \\
\hline $\begin{array}{l}\text { National Coordinators: } \mathrm{n}=9 \\
\text { Home Based Primary Care: } \mathrm{n}=14\end{array}$ & $\mathrm{n}=2$ & $\mathrm{n}=4$ & $\mathrm{n}=3$ & $\mathrm{n}=3$ & $\mathrm{~N}=35$ \\
\hline
\end{tabular}




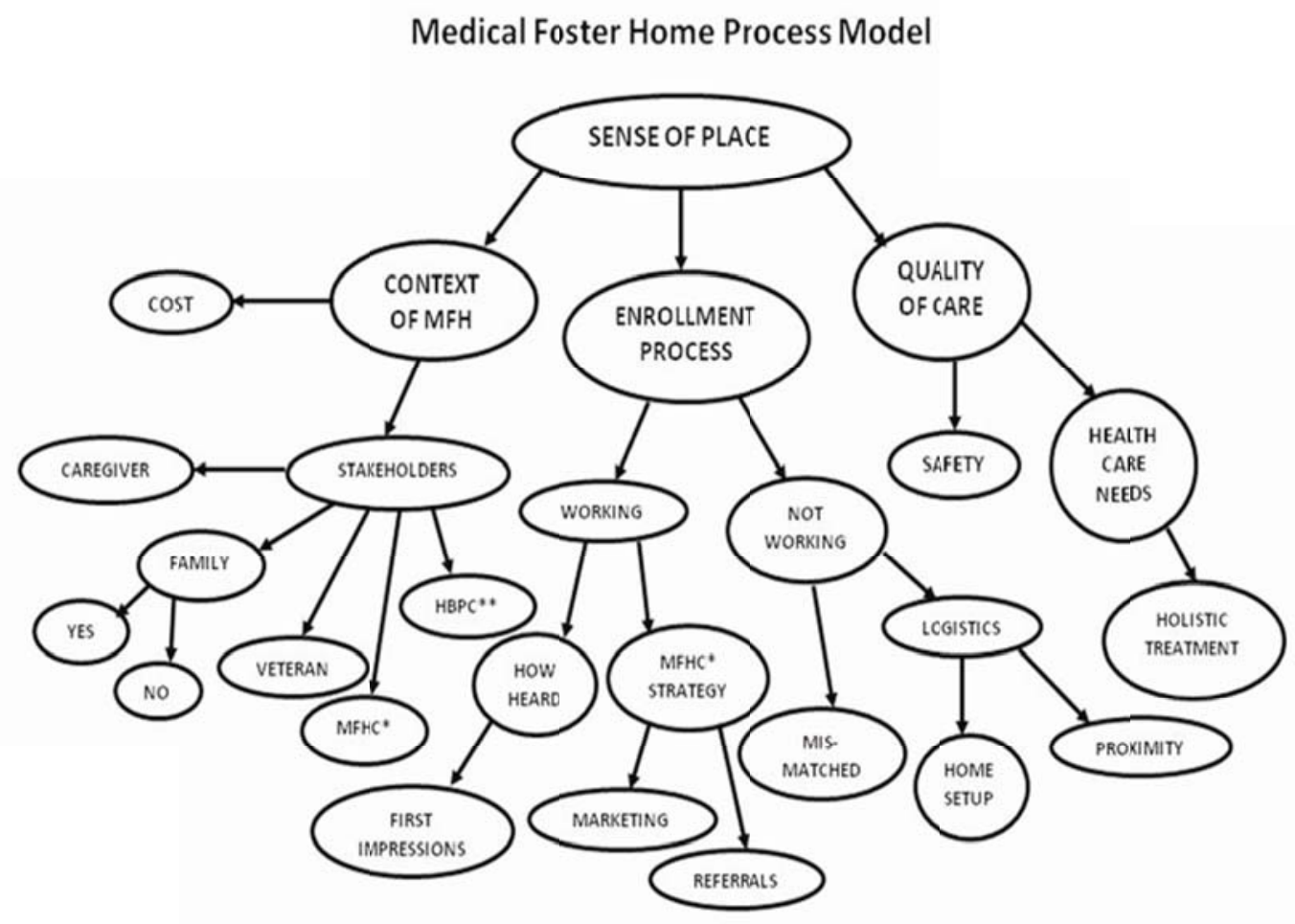

Figure 2. Medical Foster Home Process Model

\subsection{The environment}

What does a successful MFH placement look like and what are its key features in terms of structure, process, and perceived outcomes? The concept of environment encompassed not only physical space but also geographic location. Each of these factors is vital in the creation of space that is both home-like and safe.

\subsubsection{Physical space and safety}

Veterans placed in MFHs and their families generally expressed a high level of satisfaction with the MFH environment. Each Veteran had an individual bedroom and often ate meals at a shared table. MFHs were generally seen as "safe" by both Veterans and their families. "I don't feel unsafe at all here. I feel complete safety right here” (Veteran). One caregiver was reassured by her home security system and bi-monthly emergency “drills” to ensure the Veteran's ability to follow the safety procedures. In contrast, a family member of a Veteran who declined placement expressed concern about wheelchair accessibility for the Veteran even though a ramp could be quickly approved by the VA once the Veteran moved into the house: “I don’t know how fast that's going to happen...I didn’t want [Veteran] trapped... not being able to get out of the place...if there were an emergency...” (Family Member).

Both caregivers and coordinators spoke of the importance of caregiver safety and well-being. One caregiver experienced concern for her own safety after a newly placed Veteran became angry, throwing a glass at the caregiver. MFH coordinators saw caregiver safety as a key element in successful placement: “I have one Veteran who's had...a lot of problematic behavior...I want to make sure my caregiver is OK and doesn't want to do something differently or need a break” (MFH Coordinator FG).

\subsubsection{Geographic location}

The setting or location of MFHs clearly affected both Veteran and family perceptions of MFH "fit". Proximity to a family member's home was viewed as important to some while not as critical to others. Two families who declined MFH 
placement cited distant location as a barrier: “....when I told him [Veteran] where it [MFH] was, he...just kind of winced at me... I said: 'You'd probably only see me once a week.' [The caregiver] said it might be a year before they get something [closer]" (Family Member of Veteran who declined placement in MFH). One Veteran found his MFH location comforting as it was close to his previous military base, creating a sense of familiarity.

\subsection{The match: Respect and relationship}

Who are the key stakeholders involved in MFH success? Veterans, family members, and the HBPC team all stressed the importance, and challenge, of a good match between the caregiver and Veteran. The MFH Coordinator, Veteran's family, and caregiver collaborated to determine whether the home would be a good fit. Not all matches worked out initially. As one family member shared, the caregiver "...had his own opinion about what my [relative] needed, what he was going to provide and what we should provide. ...it felt like our participation wasn't welcome” (Family Member). In situations such as this, the MFH Coordinator worked swiftly with the Veteran and family to transition the Veteran smoothly to a new MFH.

\subsubsection{Feels like home}

Repeatedly Veterans, family members, and caregivers emphasized how vital it was that the MFH felt like home: "It's just natural...like home...living at home... the same care you would get there or better" (Veteran). Caregivers made a priority of creating a sense of place for the Veteran, and improving quality of life. "I allow them to live, to have a normal life. They [Veterans] are family members... I want them to feel at home” (Caregiver). One MFH coordinator spoke of her concerns about a caregiver who labeled Veterans "patients” “...I don't want them [Veterans/families] to feel like this is a nursing home” (MFH Coordinator FG).

\subsubsection{Mutual respect and family inclusion}

Family members saw the caregiver role as stressful, often without respite. They viewed the relationship between family and caregiver as a partnership to support the Veteran, described by one family member as "transparent" and "open." Maintaining a link between the Veterans' friends, family, and the HBPC team was a central goal for caregivers and they felt responsible for helping the Veterans maintain these relationships. Caregivers encouraged visits to MFH Veterans while simultaneously setting boundaries to maintain a level of respect between all involved. Overall communication between caregivers, family, and Veterans was seen as successful. Many families, HBPC team members, and MFH Coordinators expressed admiration for caregivers.

How does the MFH program facilitate Veteran engagement with the program?

\subsubsection{Key role of HBPC team}

A solid relationship between caregivers and the HBPC team was also deemed important, illustrated by one caregiver's reluctance to serve as a caregiver outside of the supportive VA MFH environment. The prompt response of the HBPC team to needs of the Veteran and caregiver, as well as the emphasis on personal safety, made the MFH a solid program. However, for one caregiver, the HBPC team was tardy: "If you call them, they will respond but not until the crisis happens” (Caregiver). Overall, caregivers felt rewarded by these relationships.

\subsection{Perceptions and expectations about Veterans' needs and MFHs}

In an effort to better understand the range of factors involved in decision-making about MFH placements, we explored first impressions on hearing the term "Medical Foster Home", progressing to priorities and expectations, both explicit and implicit, as well as challenges and concerns Veterans and family members face when considering or entering a MFH.

\subsubsection{First impressions of the term "Medical Foster Home"}

Family reactions when first hearing the term "Medical Foster Home" varied from incredulity ... "who would want to do that?...and then it also crossed my mind...that they might need the money" (Family Member of Veteran who declined 
placement in MFH) to a preconception of "foster" as a resource for abandoned beings (children without parents or animals without owners): “I didn't know they had it for Veterans, elderly people. I thought it was just for kids... who were wards of the state or didn’t have parents or their parents couldn’t care for them...” (Family Member).

\subsubsection{Expectations about Veterans' needs}

Health care needs of Veterans in MFHs included blindness, stroke, dementia, and traumatic brain injury. One caregiver noted people with dementia "can be very challenging when you are taking care of them...you need a lot of patience...continuous education... just because they don't understand and...are confused doesn't mean they're not people...” (Caregiver). Monitoring Veteran medications and adherence was another priority. One caregiver noted the high number of medications a Veteran was taking and worked with him and his care team to decrease his medications: “...in the nursing home I felt like he was overly drugged... when I [saw] his meds and how he reacted during the day, ...I wanted a better response to his living...they [HBPC] cut back on what he was taking and [now] he’s perfect” (Caregiver).

Family expectations about Veteran needs primarily centered on activities of daily living (ADLs), though some perceived needs as more holistic or all-encompassing: a son indicated that in addition to his father's basic medical, ADL, and cognitive needs, his social and sense of belonging needs were met in a meaningful way through ties with the caregiver's extended family: "They are so tight-knitted and they've really brought [Veteran] in to feel like part of their family" (Family Member). Caregiver expectations included family involvement with the Veteran at the MFH: "They [family] come once a month...I emphasize that ...somebody needs to team up with me...to volunteer” (Caregiver).

\subsubsection{Relocation challenges}

For both family and Veteran fear of the unknown was a deterrent to placement in the MFH: "A lot of times the...family members maybe haven't talked in a really long time. So there is a lot of family counseling that goes on... getting them to talk to each other" (MFH Coordinator FG). Another MFH participant noted that from the Veterans' perspective: "You take them to a home where they don't know the homeowner, maybe they met them him once or twice. 'What do I really expect from this person? Are they willing to do the things they are supposed to do? Am I going to like the food? I'm giving up a lot of independence'” (MFH Coordinator FG). Sometimes racial/ethnic prejudices hinder MFH placement: "You've got a guy who grew up his entire life [in]...an area that was predominately Irish and then you have a caregiver in a neighborhood that's Italian, black, Haitian whatever...because that person is not of the same ethnicity or religion [the Veteran will say] 'I don't want to stay there. I can't relate’” (MFH Coordinator FG).

\subsubsection{Costs}

Costs were a concern to all involved. The cost of MFH care deterred some from choosing MFH placement; for Veterans with higher health care benefit levels, however, the MFH was viewed as more affordable. One caregiver reported inadequate remuneration limited her ability to transport Veterans to outside activities. She also worried about having "enough food on the table every day" (Caregiver). A national coordinator described MFH payment as an issue for some caregivers whose motivation may have been primarily financial: "I’ve had two failed home situations, because I think that the caregivers were going in it for the money. And I don't know if they didn't have a realistic understanding of what the expectations were or what it would be like to care for someone in home or ... when they found out how much work it was, they kind of jumped ship” (MFH Coordinator FG).

\section{Discussion}

MFH is a VA community based service delivery model that is designed to meet Veterans health care needs in a private home. This evaluation highlights that at the core of successful MFH placement is the environment including the physical setting, geographic location, and safety which foster a "good fit" between the Veteran and caregiver.

Limitations include the conduct of this study in a single institution and the small sample size. However, the final phase of a general inductive approach to qualitative evaluation ${ }^{[10]}$ requires the comparison or testing of the emergent model with 
existing theory. The Social Ecological Model (SEM) provides a framework to interpret and understand the components that emerged as key factors in MFH program placement success.

What does a successful MFH placement look like and what are its key features in terms of structure, process, and perceived outcomes? This study highlights the dynamic interaction between person and environment across all levels (body, personal, caregiver, neighborhood and policy), and the interrelatedness of social elements in these environments ${ }^{[12-16]}$. By understanding the inter-relationships between, and influences within the levels of environment, the VA can more effectively modify the organizational system (macrosystem) responsible for recruitment, VA policies, the enrollment process, marketing, and costs of the program (see Figure 3). Barriers and facilitators to successful MFH placement and sustainability can be characterized both within and between layers of the MFH program at large and the relationships between each of its component parts at the personal and local level.

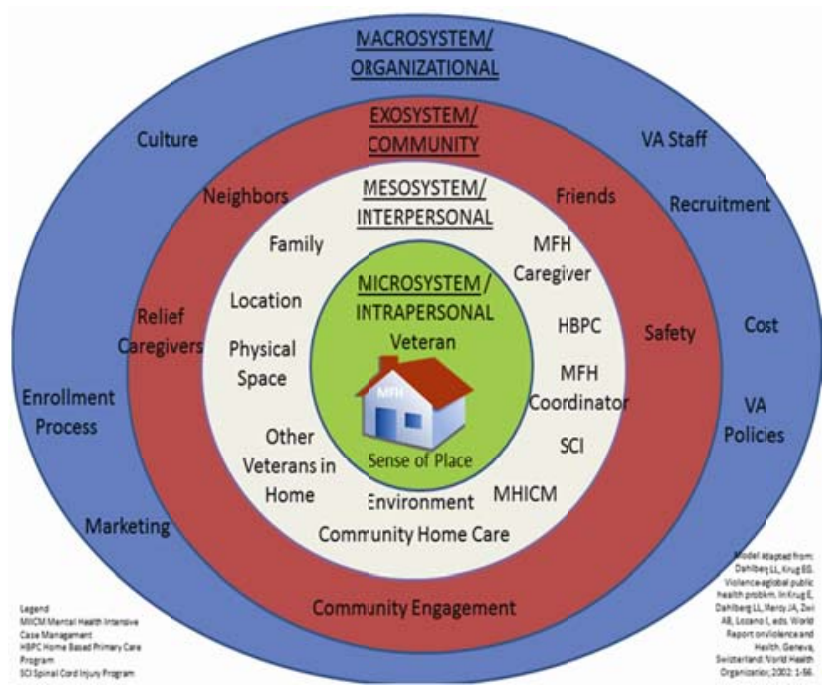

Figure 3. Conceptual Model: MFH from the Provider and Veteran Perspective

Who are the key stakeholders involved in MFH success? Key components and vital factors in creating successful MFHs (see Table 1) bridge the interpersonal domains of creating a sense of place within the local context to environmental design of physical space, location, and safety. Relationships, defined by commitment of the caregiver and expert medical support provided by the HBPC team, were equally important within the interpersonal domain and MFH level. In addition, caregiver commitment, defined as an innate sense of the intrinsic rewards of serving as a full-time caregiver, was described as essential to creating a sense of place and fostering a relationship between the Veteran and caregiver. This relationship was enhanced by mutual respect, inclusion of family in decision making, good self care among caregivers, and a good match between the Veteran and their families' communication style. The HBPC team, relief caregivers, and other members of VA care teams were also integral in fostering a healthy relationship between Veteran and caregiver. These findings are consistent with a 1976 study of 422 elderly residents of MFHs that concluded MFHs offer many advantages as long as residents are properly placed and adequate support services provided ${ }^{[17]}$.

How does the MFH program facilitate Veteran engagement with the program? Extending to the broader community, cultural and organizational domains, participants described the importance of perception and expectations which factored heavily in the initial impressions of the program. Impressions were formed beginning with beliefs about the word "foster" in the name "Medical Foster Home" and were further shaped by expectations regarding whether or not the home could meet the Veteran's health care needs and provide for the Veteran as a "whole person" by tending to functional deficits, cognitive impairments, psychosocial needs and cultural beliefs. Family members raised concerns about the expertise to manage complex medication regimens and conditions such as dementia that require specialized care giving skills and patience. 
Based on the components identified in this evaluation and, consistent with the few studies available on MFH placement, creating a "sense of place" is central to all placements with MFHs ${ }^{[18,19]}$. Simply recruiting caregivers without attention to their level of commitment to care giving, willingness to collaborate with the HBPC team, and ability to foster a sense of place will undermine this core program element and not likely lead to successful program expansion. Practical strategies participants identified may include trainings tailored to individual caregivers based on the needs of their Veteran (i.e. dementia), mentorship from other caregivers in the community, and revision of policies to allow home modifications before the Veteran moves into the home.

Two main issues surrounding costs emerged. First, using personal funds to provide payment to a MFH caregiver was seen as a barrier for some Veterans who would otherwise have their long term care funded in a NH. Second, some caregivers described monthly reimbursement as inadequate to cover all the living expenses of Veterans. Of equal importance to expansion of the program will be mitigating cost barriers. Legislation allowing VA to pay for Veterans who choose to receive care in a MFH rather than a NH may eliminate a key barrier to MFH program enrollment and would be a cost savings to VA with lower per month costs for room and board in a MFH \$1500-3000 versus a NH \$6500-\$25,000 ${ }^{[1]}$.

This evaluation, as one of the first examining components of successful adult foster care placement includes only one state's MFH program and is designed to be hypothesis-generating rather than generalizable. It suggests that the environment in which a Veteran is placed is vital to success and that more is needed beyond a medical perspective. The MFH is not intended to serve as a "mini” NH but rather an opportunity to maximize Veterans' quality of life while integrating the Veteran into the larger community. Adopting a social ecological orientation may enable the VA to re-interpret organizational and fiscal policy, examine current practice, and continue to refine the program as it expands nationally. Components of the evaluation can assist those engaging in similar non-VA programs, such as in the Medicare Independence at Home Initiative demonstration, exploring alternatives to $\mathrm{NH}$ care ${ }^{[6]}$. Future research is needed to test the relationships between MFH environment, health outcomes, safety, and cost effectiveness. The MFH model presents a new and interprofessional approach to community care. Nurses may be involved in the care of Veterans living in MFHs through the HBPC team structure or they may be involved in the referral, transition and support of Veterans and their family. Being aware of the potential the MFH model offers as an alternative to nursing home placement will be vital as we explore aging in place for veterans over time. This new MFH model offers new ways to engage with and enhance Veteran health.

\section{References}

[1] Medical Foster Homes. http://www.va.gov/GERIATRICS/Guide/LongTermCare/Medical_Foster_Homes.asp (28 March 2012, date last accessed).

[2] Costs of Care: Long Term Care Survey. http://www.genworth.com/content/non_navigable/corporate/about_genworth/industry_expertise/cost_of_care.html (13 March 2012, date last accessed).

[3] Levy C. Discharge Outcomes among Veterans Substituting Medical Foster Home Care for Nursing Home Placement. Health Services Research and Development National Conference 2012. http://www.hsrd.research.va.gov/meetings/2012/abstract-print.cfm?RecordID=508 (29 November 2012, date last accessed).

[4] Department of Veterans Affairs Office of Policy and Planning. Veteran Health care Enrollment and Expenditure Projections FY 2002-2012. http://www.va.gov/HEALTHPOLICYPLANNING/enroll02/Fnl925Doc.pdf (4 March 2013, date last accessed).

[5] Kinosian B, Stallard E, Wieland D. Projected use of long-term care services by enrolled veterans. The Gerontologist. 2006; 47: 356-364. http://dx.doi.org/10.1093/geront/47.3.356

[6] Medicare Program: Independence at Home Demonstration Program. https://www.federalregister.gov/articles/2011/12/21/2011-32568/medicare-program-independence-at-home-demonstration-progr am . 12-21-2012. 3-31-2012 (4 March 2013, date last accessed).

[7] Creswell JW. Choosing among five approaches. In Qualitative Inquiry and Research Design, 3rd Ed. Thousand Oaks, CA: Sage Publications, 2012.

[8] Sandelowski M. What's in a name? Qualitative description revisited. Research in Nursing \& Health. 2010; 33(1):77-84. PMid:20014004

[9] Wilkinson S. Analyzing focus group data. In Qualitative Research: Issues of theory, method and practice, 3rd Ed. Silverman D, ed. London: Sage Publications. 2011; 168-184.

Published by Sciedu Press 
[10] Thomas DR. A general inductive approach for analyzing qualitative evaluation data. American Journal of Evaluation. 2006; 27: 237-246. http://dx.doi.org/10.1177/1098214005283748

[11] ATLAS.ti. [6.2]. 2012. Berlin, Germany, Scientific Software Development GmbH.

[12] Rayner G. Conventional and ecological public health. Public Health. 2009; 123: 587-591. PMid:19748106 http://dx.doi.org/10.1016/j.puhe.2009.07.012

[13] Stokols D. Translating Social Ecological Theory into Guidelines for Community Health Promotion. Am J Health Promot. 1996; 10: 282-298. PMid:10159709 http://dx.doi.org/10.4278/0890-1171-10.4.282

[14] Kumar S, Quinn SC, Kim KH, Musa D, Hilyard KM, and Freimuth VS. The Social Ecological Model as a Framework for Determinants of 2009 H1N1 Influenza Vaccine Uptake in the United States. Health Education and Behavior. 2011. http://heb.sagepub.com/content/early/2011/10/07/1090198111415105

[15] Quinn LA, Thompson SJ, Ott KM. Application of the Social Ecological Model in Folic acid Public Health Initiatives. J Obstetric, Gynecologic and Neonatal Nursing. 2005; 34: 672-681. PMid:16282224 http://dx.doi.org/10.1177/0884217505281877

[16] Dahlberg LL, Krug EG. Violence-a global public health problem. In World Report on Violence and Health. Krug E, Dahlberg LL, Mercy JA, Zwi AB, Lozano R, eds. Geneva, Switzerland: World Health Organization, 2002: 1-56.

[17] Mehrotra CM, Kosloski K. Foster care for older adults: issues and evaluations. Home Health Care Serv Q. $1991 ; 12: 115-136$. PMid:10110881 http://dx.doi.org/10.1300/J027v12n01_11

[18] Mor V, Sherwood S, Gutkin C. A national study of residential care for the aged. The Gerontologist. 1986; 26 : $405-417$. PMid:3732833 http://dx.doi.org/10.1093/geront/26.4.405

[19] Bradshaw BR, Vonderhaar WP, Keeney VT, Tyler LS, Harris S. Community-based residential care for the minimally impaired elderly: a survey analysis. J Am Geriatr Soc. 1976; 24: 423-429. PMid:134052 